\title{
Engineering Properties of African Mahogany (Khaya Senegalensis) Seeds Relevant To Processing
}

\author{
Usman, D. D ${ }^{1}$, Ibrahim, M. E ${ }^{2}$, Yakubu, I. T ${ }^{3}$. And Jahun, B. G ${ }^{4}$ \\ ${ }^{1,4}$ Agricultural and Bioresource Engineering Dept., Abubakar Tafawa Balewa University, Bauchi, NIgeria \\ ${ }^{2}$ Mechanical Engineering Dept, Modibbo Adama University Of Technology, Yola, Adamawa State. \\ ${ }^{3}$ Agricultural and Environmental Engineering Dept, Modibbo Adama University of Technology, \\ Yola, Adamawa State.
}

\begin{abstract}
Khaya Senegalensis (African mahogany) seeds have been discovered to be a rich source of oil that can be used for domestic and industrial purposes. As a first step in developing processes and machine for the extraction of oil from the seeds, some physical properties namely: size, sphericity and roundness, surface area, weight, volume and density, bulk density, porosity, angle of repose and coefficient of friction (on wood and steel) and specific heat capacity were determined. The seeds which are commonly found in Adamawa state were sampled and subjected to physical property test at a moisture content of $12.20 \%$ wet basis. Major, intermediate and minor diameter varied from 14.49 to $20.59 \mathrm{~mm}, 9.47$ to $13.58 \mathrm{~mm}$ and 0.79 to $2.60 \mathrm{~mm}$ respectively, while sphericity and roundness varied from 0.34 to 0.48 and 0.43 to 0.75 . Volume and density values varied from 0.20 to $0.24 \mathrm{~cm}^{3}$ and 0.56 to $1.34 \mathrm{~g} / \mathrm{cm}^{3}$ while the weight varied from 0.10 to 0.259 . Surface area, bulk density and porosity varied from 31.41 to $66.42 \mathrm{~mm}^{2}, 0.40$ to $0.45 \mathrm{~g} / \mathrm{cm}^{3}$ and 0.42 to 0.56 respectively, while the values for coefficient of friction and angle of repose for wood and plywood varied from 0.466 to 0.601 (for plywood), 0.510 to 0.554 (steel) and $25^{\circ}$ to $32^{\circ}$ (plywood) and $27^{\circ}$ to $29^{0} \mathrm{C}$ steel respectively. Specific heat value varied from 20.77 to $32.85 \mathrm{KJ} / \mathrm{Kg}^{0} \mathrm{C}$. These results are necessary as design parameters when designing equipment for processing the seed.
\end{abstract}

Keywords: - Physical property, Specific heat, bulk density, Sphericity, coefficient of friction.

\section{INTRODUCTION}

The seed Khaya senegalensis (African mahogany) from which oil were extracted are essentially not among the popular cultivars of oil seeds like groundnut, soya bean, palm fruit and palm seed. At best they are allowed to waste away in the forest. Khaya senegalensis is an important multipurpose tree in its natural range in Africa and Madagascar (Roger, 2004). All species become big trees, $20-35 \mathrm{~m}$ tall with a trunk over $1 \mathrm{~m}$ in diameter, often buttressed at the base. The plant strives well in Riverine forest and scattered in high rainfall Savannah woodland with $700-1750 \mathrm{~mm}$ rain/year and a dry season of $4-7$ months (Dorthe and Sylvia, 2003). The plant is commonly found in Nigeria around Lagos, Ogun, Edo, Osun and Oyo states in the rain forest zone, while in the middle belt it is found around Niger, Benue, Adamawa and Taraba states (Michael, 2004). The plant begins to produce seeds when they are $15-25$ yrs and in most places fruiting is regular and the fruits remain on the tree for most of the dry season. Besides timber, rated as one of the best African mahogany wood, moderately hard with a density of $0.6-0.8 \mathrm{~g} / \mathrm{cm}^{3}$, the plant is valued for its medicinal purposes, especially the back, which is used to treat a number of diseases. The leaves are used for fodder at the end of dry season, but the forage value is low (Dorthe and Sylvia, 2003). In West Africa and Nigeria in particular, the seed oil is used as edible and for cosmetics, with an oil content of $67 \%$, comprising $21 \%$ palmatic acid, $10 \%$ stearic acid, $65 \%$ oleic acid, and 4\% unidentified acid (Dorthe and Sylvia, 2003).

During the $20^{\text {th }}$ century, the non edible use of oil seeds products decline substantially due to availability of relatively inexpensive oil derived from fossil reserves (Lea and Leegood, 1993). Though the reserves could be exhausted or becomes less in supply and are not renewable (Beolhouwer, 1983). Hence, looking into alternative oil source from various seeds remains a subject of active investigation. Khaya senegalensis seed is valued among the best in production of non-fossil oil used for various applications. Although, such oils are not expected to replace petrochemicals in their entirety, however, the processing of the seeds for the extraction of oil is mostly done traditionally and has great effect on the quality, efficiency and oil yield of the seeds. As such the need to optimize the post harvest production process which has not received significant engineering research like investigating the physical and mechanical properties of the seed that constitute an important and essential engineering data in the mechanization of its production, handling, processing and storage. Despite these little is known about the basic physical and mechanical properties of plants and animal materials. Maduoko and Hamman (2000), as well as Istifanus (2006) emphasized the need for the characterization of agricultural materials in terms of their physical, mechanical thermal, electrical and optical properties necessary in the design 
of machines for post harvest handling and processing. Alcali and Guyen (1990), as well as Olaoye (2000) observed that a rational approach to the design of agricultural machinery equipment and facilities involves a theoretical analysis of the effect of the physical properties of the agricultural product on the characteristics of the machinery, facilities and process or operation. However, this research objective is to investigate some physical properties of Khaya senegalensis seed which include shape and size, sphericity, roundness, volume, weight, surface area, static coefficient of friction against steel and plywood, angle of repose and specific heat capacity.

\section{MATERIAL AND METHODS}

All the seeds were collected from crop science department, Federal University of Technology Yola, north and Yola south local government area, and Michika local government area respectively during their annual season availability in 2010. The good quality seed were handpicked to separate them from bad ones. Since the seed is an oil seed, moisture content was determined by oven drying the seeds at a temperature of $105^{\circ} \mathrm{C}$ and a time of 4 hours (Istifanus, 2006). Moisture content was found to be $12.20 \%$ wb.

One hundred seeds were randomly selected from the sample. Measurements of dimensions on three naturally perpendicular axes were made, namely: major, intermediate and minor diameters. These dimensions were measured with electrical digital Vernier Calipers with a resolution, reliability and maximum error of 0.01 $\mathrm{mm}, 0.01 \mathrm{~mm}$ and $0.02 \mathrm{~mm}$ respectively.

Sphericity and roundness were determined for the seeds. Each seed was placed in its natural resting position on a sheet of graph paper. A sharp pencil was used to carefully trace the edge of seed. Projected area and the diameters of circles inscribing and circumscribing the projected areas were measured (Oje and Ugbor 1991), and sphericity and roundness were determined using these equations:

$$
\begin{array}{r}
\text { Roundness }=\frac{\mathrm{A}_{\mathrm{P}}}{\mathrm{A}_{\mathrm{C}}} \\
\mathrm{S}(\Phi)=\frac{(L W T)^{\frac{1}{3}}}{L}
\end{array}
$$

The volume and hence density of 50 seeds each was determined by the water displacement method as described by Ojo and Ugbor (1991). Individual seed were immersed in water inside a measuring cylinder sharing a notably rise in water level. The difference in the final and initial reading was recorded as the volume of the seed. Density was determined by dividing weight by volume.

The surface area of 100 seeds each was determined using:

$$
\mathrm{S}=\left(\mathrm{D}_{\mathrm{P}}\right)^{2}
$$

As described by Fraser et al, (1978).

Bulk density was obtained using

$$
\mathrm{D}_{\mathrm{b}}=\frac{\mathrm{M}_{2}-\mathrm{M}_{1}}{\mathrm{~V}}
$$

Empty $132 \mathrm{~cm}^{3}$ cylinder was weighed, then filled with the Khaya seeds and reweighed. Computation was done using equation 4.

The porosity was obtained from the relationship as stated by Mohsenin (1988)

$$
\mathrm{P}_{\mathrm{f}}=1-\frac{\Delta_{b}}{\Delta_{s}}
$$

The angle of repose and coefficient of friction were determined with respect to two structural materials namely: plywood and galvanized steel. An inclined plane apparatus was used to obtain the angle of repose by placing some amount of seeds on an adjustable tilting surface. It was gradually raised with a crew device until it just start to slide down the angle of the incline was read from a graduated scale. The coefficient of friction was obtained from the relationship as described by Mohsenin (1988).

$$
\mu=\tan \alpha
$$

Specific heat capacity was determined by the method of mixture (Ojo and Ugbor, 1991) using an adiabatic drop calorimeter. Water of known weight and temperature was poured into a calorimeter containing the seeds. At equilibrium, the final temperature was noted. Specific heat capacity Cs, was calculated by the expression 


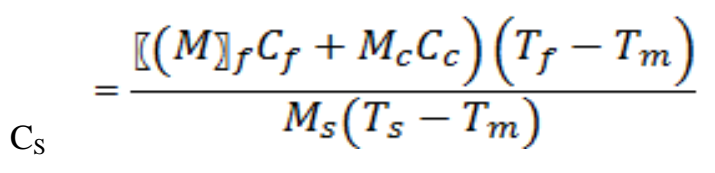

III. RESULTS AND DISCUSSION Results

Table 1: Measured Parameters

\begin{tabular}{cclrrr}
\hline Parameters & & Replica & Max. Min. & Mean \\
\hline Major dia & $\mathrm{mm}$ & 100 & 20.59 & 14.49 & 17.52 \\
Inter. dia & $\mathrm{mm}$ & 100 & 13.58 & 4.49 & 11.79 \\
Minor dia & $\mathrm{mm}$ & 100 & 2.60 & 0.79 & 1.52 \\
Weight & $\mathrm{g}$ & 100 & 0.27 & 0.11 & 0.18 \\
Angle of Repose & & & & \\
Steel surface $\left(^{\circ}\right)$ & 50 & 29 & 27 & 27.85 \\
Wood surface $\left(^{\circ}\right)$ & 50 & 32 & 25 & 29.60 \\
\hline
\end{tabular}

Table 2: Calculated Parameters

\begin{tabular}{|c|c|c|c|c|}
\hline Parameters & Replica & Max. & Min. & Mean \\
\hline Surface area $\left(\mathrm{mm}^{2}\right)$ & 100 & 66.42 & 31.14 & 48.85 \\
\hline Roundness & 100 & 0.75 & 0.43 & 0.58 \\
\hline Sphericity (mm) & 100 & 0.48 & 0.34 & 0.54 \\
\hline Volume $\quad\left(\mathrm{cm}^{3}\right)$ & 100 & 0.25 & 0.18 & 0.21 \\
\hline Density $\left(\mathrm{g} / \mathrm{cm}^{3}\right)$ & 100 & 1.34 & 0.56 & 0.88 \\
\hline Bulk density & 50 & 0.45 & 0.40 & 0.42 \\
\hline $\begin{array}{l}\text { Porosity } \\
\text { Coeff of friction }\end{array}$ & 50 & 0.56 & 0.42 & 0.51 \\
\hline Steel surface $\left({ }^{\circ}\right)$ & 50 & 0.55 & 0.51 & 0.53 \\
\hline Wood surface $\left({ }^{\circ}\right)$ & 50 & 0.60 & 0.47 & 0.57 \\
\hline Specific heat $(\mathrm{KJ} / \mathrm{KgS})$ & 50 & 37.22 & 20.80 & 27.94 \\
\hline
\end{tabular}

\section{DISCUSSION}

The sizes were determined along the major, minor and intermediate axes. The mean values and ranges (table 1) of the seeds along major axis were $17.52 \mathrm{~mm}$ and 20.54 to $14.49 \mathrm{~mm}$, along the major axis, $1.5 \mathrm{~mm}$ and 2.60 to $0.79 \mathrm{~mm}$ along minor axis, and $11.70 \mathrm{~mm}$ and 13.58 to $9.47 \mathrm{~mm}$ along the intermediate axis respectively. A positive correlation was established between the seed length, width and thickness with other parameters of the seeds at 0.01 significant level (Appendix 1). The sizing of the seed dimension is important in aperture design of machine. The seeds dimension was observed to differ with those reported for pea seeds (Poksay and Aydin, 2006), and sunflower seeds (Gupta and Das 1997).

The weights were determined at $12.20 \% \mathrm{mc}(\mathrm{wb})$ with a mean value of 0.18 and ranges from 0.10 to 0.259. The values were higher than those of sufflower seeds at 9.2\% mc (wb) (Turkan et al, 2006). Positive correlation was established between weight of Khaya seeds and its density and volume at 0.01 significant level. Similar trend was reported for pea seed between its weight and moisture content (Poksoy and Aydin, 2006).

The angle of repose for the seed was observed to vary from $32^{\circ}$ to $25^{\circ}$ with a mean value of $29.6^{\circ}$ for plywood, while the mean value and ranges for galvanized steel were 26.85 and $29^{\circ}$ to $27^{\circ}$ respectively. The angle of repose for the seeds was less than those of sunflower (Gupta and Das, 1997). A positive correlation was also established between the seed angle of repose and coefficient of friction at 0.01 level of significance.

The surface area of the seed was evaluated and the mean value was found to be $48.85 \mathrm{~mm}^{2}$, and varies from 31.14 to $66.42 \mathrm{~mm}^{2}$. The surface area will aid in the study of heat transfer in the heating and cooling processes and in machine design especially for the mechanical expression of oil from the seeds as reported by Mohsenin (1988). A positive correlation was observed between surface area of the seed with its length, width, thickness and sphericity at 0.01 significant levels.

The mean values of sphericity and roundness of the seeds were evaluated as 0.54 and 0.58 while they range from 0.34 to 0.48 and 0.43 to 0.75 respectively. The values of sphericity was similar to those reported for sunflower seeds but lower for pigeon pea and soya bean seeds (Gupta and Das, 1997). The results indicated the seed would rather slide than role which will aid in design of hopper, loading and unloading devices. Sphericity correlates positively with seed thickness and surface area while roundness correlates positively with seed thickness at 0.01 significant levels. 
The mean value and density of Khaya seeds were obtained as $0.21 \mathrm{~cm}^{3}$ and $0.8891 \mathrm{~cm}^{3}$ while they vary from 0.20 to $0.24 \mathrm{~cm}^{3}$ and 0.56 to $1.34 \mathrm{~g} / \mathrm{cm}^{3}$ respectively. The value was found to be similar to those sunflower seed at $4.47 \% \mathrm{mc}$ (Turka et al, 2006). Also positive correlation exists between volume and density with the seed weight.

Bulk density of khaya seed have a mean value of $0.42 \mathrm{~g} / \mathrm{cm}^{3}$ and varies from 0.40 to $0.45 \mathrm{~g} / \mathrm{cm}^{3}$, there was no relationship between bulk density and other parameters obtained for the khaya seeds. However, porosity varies from 0.42 to 0.56 with a mean of 0.51 . The porosity of Khaya seed was higher than those of sunflower, sufflower, and pumpkin seed (Joshi et al, 1993; Desphade et al, 1993 and Gupta and Prakash, 1992). Correlation was not established between porosity and other parameters determined.

Static coefficient of friction for the Khaya seed was determined and ranges from 0.601 to 0.466 for wooden surface with a mean value of 0.567 , while for galvanized steel, it varies from 0.554 to 0.510 with a mean value of 0.528 respectively. Values were higher for wooden surface than for steel surfaces. The static coefficient of friction of the seeds on steel surface is similar to those of sunflower seeds on galvanized iron surface while it is higher for sufflower, grains, and oil bean seed (Gupta and Das, 1997). A positive correlation exists between coefficient of friction for steel surface and angle for repose for steel surface at 0.01 significant levels.

The specific heat capacity of Khaya seed were evaluated and found to vary from 20.77 to 32.85 $\mathrm{KJ} / \mathrm{Kg}^{\circ} \mathrm{C}$. These results are higher than those reported for palm kernel seeds (Gbadamosi, 2006).

\section{CONCLUSION}

The determination of some physical properties of Khaya seed at a moisture content of $12.20 \%(\mathrm{db})$ have revealed vital facts on design consideration with respect to oil extraction from the seed. The mean values of its dimension, sphericity roundness, volume and density were found to be $17.52 \mathrm{~mm}, 11.79 \mathrm{~mm}, 1.52 \mathrm{~mm}$ (Major, intermediate and minor diameter), $0.54,0.58,0.21 \mathrm{~cm}^{3}$ and $0.88 \mathrm{~g} / \mathrm{cm}^{3}$ respectively. This indicates that the seed will slide rather than roll because of low coefficient of friction hence in the design of hopper it should not be too steep. Also, the mean value of weight, surface area, bulk density, porosity angle of repose(for wood and steel surfaces), coefficient of static friction and specific heat capacity were $0.18 \mathrm{~g}, 48.85 \mathrm{~mm}^{2}, 0.42 \mathrm{~g} / \mathrm{cm}^{3}$, $0.51,29.60^{\circ}$ (plywood), $27.85^{\circ}$ (steel), 0.57 (plywood), 0.53 (steel) and $27.94 \mathrm{~kg} / \mathrm{kg}^{0} \mathrm{C}$. These results would play a very important role in understanding the agronomic properties of the seed when designing processing or handling machine for the seed.

\section{REFERENCES}

[1] Roger, A., Khaya senegalensis - current use from it's natural range and it's potential in Sri-Lanka and elsewhere in Asia. CSIRO and Forest Research, Kingston. ACT 2604. 2004.

[2] Dorthe, J. and Sylvie, G. Khaya senegalensis (Desr)-Taxonomy and nomenclature. Seed leaflet, No 66, 2003. http://74.125.45.132/search?q=cache:t2k8gDE7YAJ.

[3] Food Security:info/food-security.inf.

[4] Michael, A. Trees, shrubs and lianas of West Africa dry zones. (CIRAD Muggraf Publishers GMBH. MNHN.Pp 355, 2004)

[5] Lea, P.J. and Leegood, R.C. , Plant Biochemistry and Molecular Biology (Chister John Willey, P. 269. 1993)

[6] Beolhouwer, C., Trends in Chemistry and technology of Lipids. J. Am. Oil chemists Soc. 1983, 60:457462.

[7] Maduako, J.N. and Hamman, M., Physical Properties of some groundnut varieties for the mechanization of shelling operation. A paper presented at the National Conference on the Revitalization of Agriculture in the Nigeria Economy FUT-Yola, 2000, Pp. $74-79$.

[8] Istifanus, A. B. (2006). A study of source mechanical properties of bambara nut [Vigna subterranean (L) verde] M.Sc. Thesis, Department of Agric Eng. FUT-Yola, 2006, Pp 6-21.

[9] Alcali, I.D. and Guyen, O., Physical properties of peanut in Turkey, Agricultural Mechanization in Asian, African and Latin American, 2(3), 1990, 5559.

[10] Olaoye, J.O., Some physical Properties of Castor Nut relevant to the design of processing equipment. Journal of Agricultural engineering research. 77 (1), 2000, 113 - 118.

[11] Oje, K. and Ugbor, E.C., Some physical properties oil bean seed. Journal of Agric Eng. Res. 50, 1991, $305-313$.

[12] Fraser, B.M., Verma, S.S. and Muir, W.E., Sources Physical Properties of Fababeans. J. Agric Eng. Res., $23,1978,53-57$.

[13] Mohsenin, N.N. (1988). Physical properties of plant and animal materials. New York. Garden and Breach Science Publishers Inc. N.Y. 1988. 
[14] Paksoy, M. and Aydin, C., Determination of some physical and mechanical properties of pea (Pisum satiuum L.) seed. Pakistan Journal of Biological Sciences. 9(1), 2006, 26 - 29.

[15] Turkan, A., Iiker, A and Durgut, R., Some Physical and Mechanical properties of Safflower seeds (Carthamius tinctorius L), Journal of Agronomy. 5(4), 2006, 613 - 616.

[16] Joshi, D.C., Das, S.K. and Mukherjee, R.K., Physical Properties of pumpkin seeds. J. Agric Eng. Res. 54, 1993, $219-229$.

[17] Desphande, S.D., Bal, S. and Ojha, T.P. (1993). Physical Properties of Soya bean. J. Agric. Eng. Res. 56, $1993,89-98$.

\section{Notations}

Ap - Largest projected area of seed in rest position

Ac - Area of smallest circumscribed circle

$\mathrm{Dp}$ - Geometric mean diameter of seed

$\mathrm{M}_{2}$ - Mass of cylinder plus seed

$\mathrm{M}_{1}$ - Mass of empty cylinder

$\mathrm{Db}-$ Bulk density of seed

Ds - Density of seed

$\mathrm{M}_{\mathrm{f}}$ - Mass of water

$\mathrm{C}_{\mathrm{f}}$ - Specific heat capacity of water

$\mathrm{Mc}$ - Mass of calorimeter

$\mathrm{Cc}-$ Specific heat capacity of calorimeter

Ms - Mass of seed

$\mathrm{Tt}$ - Initial temperature of water

$\mathrm{Tm}$ - Initial temperature of mixture

Ts - Initial temperature of seed

$\mathrm{F}$ - Force

L - Length of seed

W - Width of seed

$\mathrm{T}-$ Thickness of seed. 